\title{
OsGF14b Positively Regulates Panicle Blast Resistance but Negatively Regulates Leaf Blast Resistance in Rice
}

\author{
Qing Liu, ${ }^{1,2}$ Jianyuan Yang, ${ }^{3}$ Shaohong Zhang, ${ }^{1,2}$ Junliang Zhao, ${ }^{1,2}$ Aiqing Feng, ${ }^{3}$ Tifeng Yang, ${ }^{1,2}$ \\ Xiaofei Wang,,$^{1,2}$ Xinxue Mao, ${ }^{1,2}$ Jingfang Dong, ${ }^{1,2}$ Xiaoyuan Zhu, ${ }^{3}$ Hei Leung, ${ }^{4}$ Jan E. Leach, ${ }^{5}$ \\ and Bin Liu',
}

\begin{abstract}
${ }^{1}$ Guangdong Key Laboratory of New Technology in Rice Breeding, Guangzhou 510640, China; ${ }^{2}$ Rice Research Institute, Guangdong Academy of Agricultural Sciences, Guangzhou 510640, China; ${ }^{3}$ Guangdong Key Laboratory of New Technology in Plant Protection, Plant Protection Research Institute, Guangdong Academy of Agricultural Sciences; ${ }^{4}$ Plant Breeding, Genetics and Biotechnology Division, International Rice Research Institute, DAPO Box 7777, Metro Manila, Philippines; and

${ }^{5}$ Bioagricultural Sciences and Pest Management, Colorado State University, Fort Collins 80537-1177, U.S.A.
\end{abstract}

Submitted 7 March 2015. Accepted 1 October 2015.

\begin{abstract}
Although 14-3-3 proteins have been reported to be involved in responses to biotic stresses in plants, their functions in rice blast, the most destructive disease in rice, are largely unknown. Only $G F 14 e$ has been confirmed to negatively regulate leaf blast. We report that $G F 14 b$ is highly expressed in seedlings and panicles during blast infection. Rice plants overexpressing $G F 14 b$ show enhanced resistance to panicle blast but are susceptible to leaf blast. In contrast, GF14b-silenced plants show increased susceptibility to panicle blast but enhanced resistance to leaf blast. Yeast one-hybrid assays demonstrate that WRKY71 binds to the promoter of $G F 14 b$ and modulates its expression. Overexpression of $G F 14 b$ induces expression of jasmonic acid (JA) synthesis-related genes but suppresses expression of salicylic acid (SA) synthesis-related genes. In contrast, suppressed $G F 14 b$ expression causes decreased expression of JA synthesis-related genes but activation of SA synthesisrelated genes. These results suggest that $G F 14 b$ positively regulates panicle blast resistance but negatively regulates leaf blast resistance, and that $G F 14 b$-mediated disease resistance is associated with the JA- and SA-dependent pathway. The different functions for 14-3-3 proteins in leaf and panicle blast provide new evidence that leaf and panicle blast resistance are controlled by different mechanisms.
\end{abstract}

Rice blast, caused by Magnaporthe oryzae, is one of the leading causes of yield loss in rice worldwide. A common problem in rice production is the short life of blast disease resistance in rice cultivars and, as a result, understanding how to extend the life span of blast resistance is a priority in rice improvement. Based on the infected parts, rice blast is classified as leaf blast and panicle blast. Compared with leaf blast, panicle blast is more destructive in terms of yield loss (Dai et al. 2007; Zhuang et al. 2002). Although positive correlations are generally observed between leaf blast resistance and panicle blast resistance, this is not always the case (Zhuang et al. 2002). Our recent evaluation of leaf and panicle blast resistance in 31

Corresponding authors: B. Liu; E-mail: 1bgz1009@163.com; and X. Zhu; E-mail: gzzhuxy@tom.com

*The $e$-Xtra logo stands for "electronic extra" and indicates that nine supplementary figures and one supplementary table are published online.

@ 2016 The American Phytopathological Society near-isogenic lines showed that several lines exhibited resistance to leaf but not panicle blast or vice versa (unpublished data). Furthermore, our genome-wide gene expression profiling of two contrasting rice varieties after challenge of leaves and panicles with the rice blast pathogen showed that, while some differentially expressed genes overlapped, others were clearly differently expressed between plants showing leaf versus panicle blast (unpublished data). These results suggest that the mechanisms of leaf and panicle blast resistance are different in rice. However, to date, almost all studies on rice blast resistance mechanisms are based on leaf blast. Thus, we have very limited knowledge about rice gene functions or regulatory mechanisms governing panicle blast resistance. Because the mechanisms may be different, it is necessary to understand gene functions in both leaf and panicle blast resistance before they can be effectively used for control of blast disease in rice.

In general, rice blast resistance can be manifested in two ways, qualitative (complete) resistance mediated by major disease resistance $(R)$ genes and quantitative (partial) resistance contributed by multiple genes or quantitative trait loci (QTL) (Kou and Wang 2010; Fu et al. 2011). Qualitative resistance conferred by $R$ genes is highly efficient; however, it is race specific and this type of resistance may be easily overcome owing to the rapid evolution of pathogens (Fu et al. 2011; McDonald and Linde 2002). In contrast, quantitative resistance conferred by QTL is presumably nonrace specific and is generally considered to be more broad spectrum and durable in natural conditions (Kou and Wang 2010). Although quantitative resistance is the preferred strategy for blast control and more than 300 quantitative blast-resistant QTL have been identified (Ballini et al. 2008), marker-assisted selection (MAS) for quantitative disease resistance has not been effectively used for blast control. The polygenic nature of quantitative resistance, the small effect of each QTL, and the low resolution of QTL mapping due to insufficient recombination make MAS for quantitative blast resistance difficult. Therefore, isolation and characterization of the genes underlying quantitative blast resistance is the key for effective use of quantitative disease resistance for blast control.

Map-based cloning has been widely used for isolation of major resistance genes with stronger effects. Thus far, 21 blast resistance genes have been cloned (Liu et al. 2013). However, it is difficult to use the same approach to isolate quantitative blast resistant QTL due to their polygenic nature and smaller effect of each QTL (Hu et al. 2008), and new strategy should be 
adopted. In recent years, much progress on plant defense responses (DR) has been made (Dodds and Rathjen 2010; Jones and Dangl 2006). DR genes are recognized based on their increased expression pattern during plant defense (Liu et al. 2004). The proteins encoded by these genes include (i) structural proteins that are incorporated into the extracellular matrix and participate in the confinement of the pathogen, (ii) enzymes of secondary metabolism, and (iii) enzymes implicated to be directly involved in the DR. $D R$ genes are generally considered to be downstream from the recognition step of the signal transduction pathway and their products are thought to enhance defense in a quantitative manner (Ramalingam et al. 2003; Young 1996). Our previous study demonstrated that the five $D R$ genes encoding putative oxalate oxidase, dehydrin, PR-1, chitinase, and 14-3-3 protein accounted for 30.0, 23.0, 15.8, 6.7 , and $5.5 \%$, respectively, of blast diseased leaf area (DLA) variation and colocalized with resistance QTL identified by interval mapping (Liu et al. 2004). Additionally, many QTL conferring quantitative resistance to several important plant diseases colocalize with candidate $D R$ genes (Fu et al. 2009; Fukuoka et al. 2009; Ramalingam et al. 2003; Wu et al. 2004). Based on these results, a candidate gene strategy to isolate disease resistance QTL in rice was proposed ( $\mathrm{Hu}$ et al. 2008; Liu et al. 2004; Manosalva et al. 2009). Using this strategy, for example, Hu et al. (2008) showed that four candidate genes influenced rice interactions with Xanthomonas oryzae pv. oryzae or $M$. oryzae. These results suggest that candidate defense gene approach is a good strategy for isolation of disease resistance QTL, leading to a better understanding of the mechanisms for quantitative disease resistance.

The 14-3-3 gene family has been reported to be involved in disease resistance in various crop plants (Finnie et al. 2002; Liu et al. 2004; Manosalva et al. 2011; Yang et al. 2009). The 14-3-3 proteins are ubiquitous in eukaryotic organisms (Rosenquist et al. 2000). They act as phosphoserine-binding proteins that regulate the activities of a wide array of targets via direct protein-protein interactions (Oecking and Jaspert 2009; Roberts 2003; Shin et al. 2011). An increasing number of transcription factors and signaling proteins are now recognized as 14-3-3interacting proteins. For example, 14-3-3 proteins interact with plasma membrane $H^{+}$-ATPases in barley epidermal cells as they respond to infection by the powdery mildew fungus, and the interaction is postulated to be important for triggering programmed cell death (PCD) (Finnie et al. 2002). The Arabidopsis 14-3-3 protein $\mathrm{G} F 14-\lambda$ interacts with the RPW8.2 protein to confer resistance to the fungal pathogen Golovonomyces spp. (Yang et al. 2009). Additionally, the tomato (Solanum lycopersicum) 14-3-3 protein 7 directly interacts with mitogen-activated protein (MAP) kinase kinase kinase MAPKKKa to positively regulate immunity-associated PCD (Oh et al. 2010). More recently, rice $14-3-3$ protein $(\mathrm{GF} 14 \mathrm{e})$ was shown to negatively regulate resistance against both biotrophic and necrotrophic pathogens, providing the first direct evidence that 14-3-3 proteins play negative regulatory roles in broad-spectrum resistance (Manosalva et al. 2011).

The rice 14-3-3 protein gene family has eight members named GF14a through GF14h (Chen et al. 2006). Previous studies indicated that $G F 14 b$ and $G F 14 f$ may interact with mitogen-induced MAP kinase 1 (BIMK1), which was induced by rice blast infection and participates in systemic acquired disease resistance (Cooper et al. 2003). Four family members (GF14b, GF14c, GF14e, and GF14f) were significantly induced by $M$. oryzae (Chen et al. 2006). Taken together, these results support the idea that rice 14-3-3 proteins may play important roles in rice blast resistance. Thus far, speculation on the possible functions of 14-3-3 proteins in blast resistance has been based on their transcription changes after pathogen challenge and the colocalization of 14-3-3 genes with blast resistance QTL (Chen et al. 2006; Liu et al. 2004). Only GF14e has been confirmed to play a negative role in leaf blast resistance (Manosalva et al. 2011). The functions of the other members of the 14-3-3 gene family in blast resistance are still unknown. In particular, we have no information about the effect of 14-3-3 proteins on panicle blast and their roles in the regulation of responses to blast in rice.

In the present study, we show that $G F 14 b$ expression is induced during panicle blast infection but is slightly repressed during leaf blast infection. Through gene overexpression and silencing experiments, we demonstrate that $G F 14 b$ positively regulates panicle blast resistance while negatively modulating leaf blast resistance. Our results also suggest that $G F 14 b$ is regulated by $W R K Y 71$ and $G F 14 b$-mediated blast resistance is associated with jasmonic acid (JA) and salicylic acid (SA) signaling pathways.

\section{RESULTS}

\section{$G F 14 b$ exhibits different expression patterns} during leaf blast and panicle blast infection.

To investigate the roles of $G F 14 b$ in leaf and panicle blast resistance, the gene expression changes were assayed by realtime polymerase chain reaction (PCR) at $6,12,24$, and $48 \mathrm{~h}$ after leaf and panicle inoculation with $M$. oryzae, respectively. Our results showed that $G F 14 b$ expression is induced during infection of panicle blast but is slightly suppressed during infection of leaf blast (Fig. 1A). GF14b expression in infected panicles peaked at $48 \mathrm{~h}$ after inoculation. These results suggest that $G F 14 b$ positively regulates panicle blast resistance and negatively regulates leaf blast resistance.

A

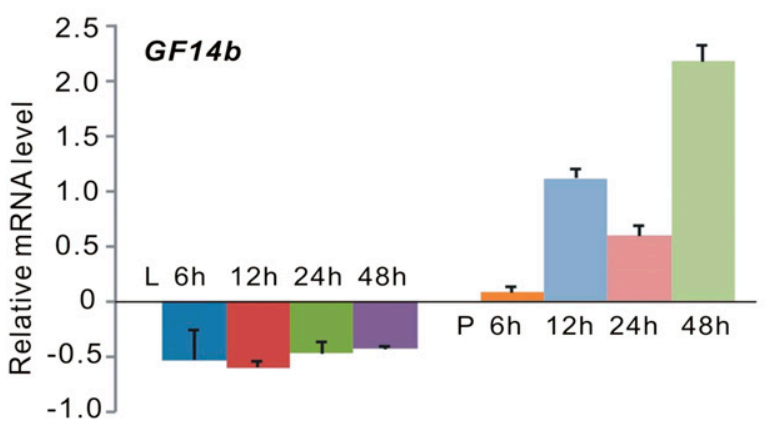

B
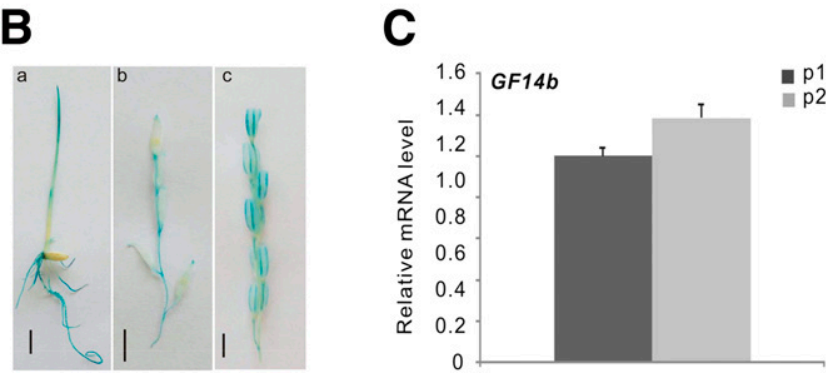

Fig. 1. Expression pattern of $G F 14 b$ in wild-type rice Nipponbare plants after infection with Magnaporthe oryzae. A, Expression pattern of the GF14b gene during development of leaf (left) and panicle (right) blast disease as assessed by real-time polymerase chain reaction (PCR) at 6, 12, 24 , and $48 \mathrm{~h}$ after inoculation; $\mathrm{L}=$ leaf inoculation and $\mathrm{P}=$ panicle inoculation. B, Histochemical analysis of $\beta$-glucuronidase (GUS) activity in seedlings and panicles of Nipponbare expressing the $G F 14 b$ promoter-GUS chimeric gene at different plant developmental stages: a, 1-week-old seedling; $\mathbf{b}$, panicle at the booting stage; and c, panicle at the heading stage. C, Real-time PCR expression analysis of $G F 14 b$ in panicles at booting (p1) and heading (p2) stages. 
$G F 14 b$ is highly expressed in roots, leaves of seedlings, and panicles.

To understand the temporal and spatial expression of $G F 14 b$ in rice plants, we generated transgenic 'Nipponbare' lines in which expression of a $\beta$-glucuronidase (GUS) was driven by a 1,600 -bp region upstream from the translational start site of $G F 14 b$. Histochemical analysis of GUS activity revealed that

A

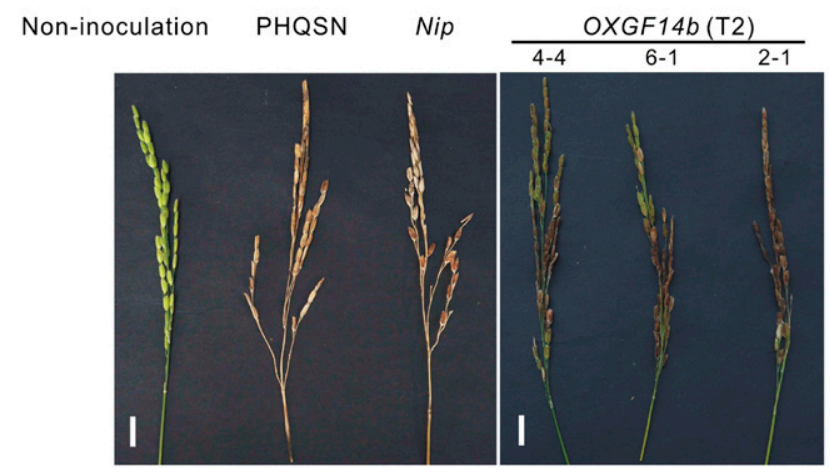

B
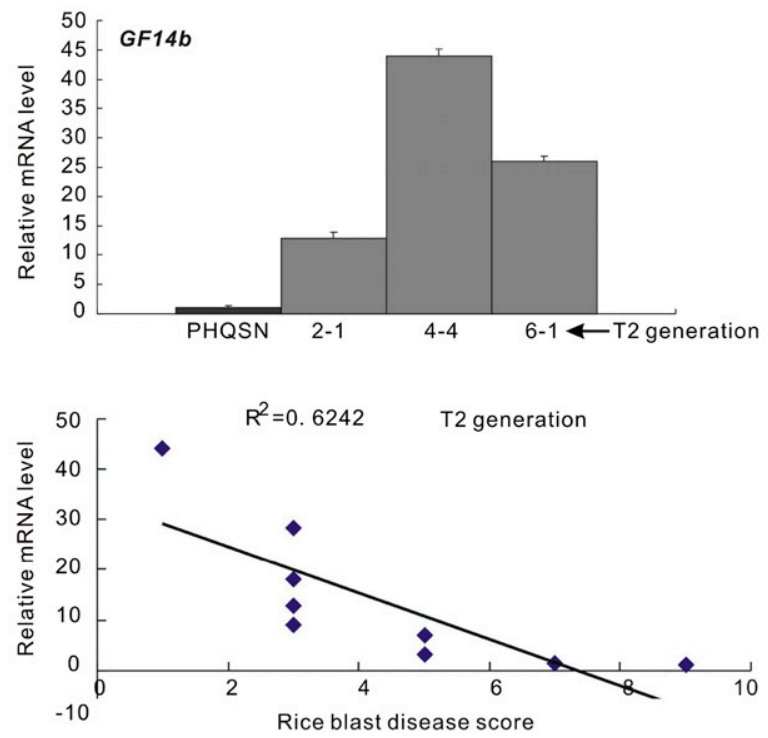

Fig. 2. Rice plants overexpressing GF14b (OXGF14b) show enhanced resistance to panicle blast infection. A, Overexpression of $G F 14 b$ improves the resistance to panicle blast. PHQSN is the empty vector control. Scale bar $=2 \mathrm{~cm}$. B, OXGF14b mRNA levels, as measured by real-time polymerase chain reaction, show overexpression of the gene in three $\mathrm{T}_{2}$ transgenic plants. C, Enhanced resistance to panicle blast is associated with increased levels of $G F 14 b$ expression in $\mathrm{T}_{2}$ transgenic plants.

Table 1. Evaluation of panicle blast resistance of $G F 14 b$-overexpressing $\left(\mathrm{OXGF14b)}\right.$ plants $\left(\mathrm{T}_{2} \text { generation }\right)^{\mathrm{a}}$

\begin{tabular}{lccc}
\hline $\begin{array}{l}\text { Line or } \\
\text { variety }\end{array}$ & $\begin{array}{c}\text { Total } \\
\text { number }\end{array}$ & $\begin{array}{c}\text { Infected main } \\
\text { axis length }(\%)\end{array}$ & P value \\
\hline PHQSN & 9 & $83.33 \pm 8.66$ & $\ldots$ \\
Nipponbare & 5 & $82 \pm 8.36$ & 0.3924 \\
$O X G F 14 b(2-1)$ & 5 & $35 \pm 7.07$ & $9.38172 \mathrm{E}-08^{* * *}$ \\
$O X G F 14 b(4-4)$ & 9 & $33.88 \pm 6.02$ & $9.91412 \mathrm{E}-11^{* * *}$ \\
$O X G F 14 b(6-1)$ & 11 & $34.54 \pm 6.05$ & $1.74801 \mathrm{E}-11^{* * *}$ \\
\hline
\end{tabular}

a Total number $=$ the sum of the inoculated panicles. The panicle blast resistance of a given line is evaluated by measuring the percent infected main axis length. Percent infected main axis length $=$ infected main axis length/main axis length of the inoculated panicle $\times 100$. Each value represents the mean \pm standard error. $P$ value is calculated using PHQSN as control and *** indicates $P<0.001$. the $G F 14 b$ promoter is highly activated in roots, shoots, and branches of panicles (Fig. 1B). Interestingly, GUS activity was observed in branches but not glume shells at the booting stage. However, GUS activity was detected in both branches and glume shells at the heading stage, suggesting higher levels of $G F 14 b$ gene expression at the heading stage. Real-time PCR experiments confirmed that $G F 14 b$ is more highly expressed at heading relative to booting stages (Fig. 1C). Because panicle blast usually occurs at the heading stage, the higher expression of $G F 14 b$ during heading is consistent with a role in regulation of panicle blast resistance.

\section{Overexpression of $\mathrm{GF} 14 \mathrm{~b}$ enhances rice resistance} to panicle blast but has no effect on leaf blast resistance.

To determine the effects of GF14b expression on leaf and panicle blast, transgenic rice plants constitutively overexpressing $G F 14 b$ were produced in Nipponbare, which is highly susceptible to $M$. oryzae isolate GD08-T13. The transgenic plants exhibited no morphological changes and were fertile. $\mathrm{T}_{0}$ overexpression plants exhibited significantly enhanced resistance to panicle blast (Supplementary Fig. S1A), and real-time PCR experiments confirmed that the enhanced resistance is associated with increased accumulation of $G F 14 b$ transcripts (Supplementary Fig. S1B). To verify that enhanced panicle blast resistance was due to the overexpression of $G F 14 b$, three transgenic lines (lines 2, 4, and 6) that exhibited enhanced resistance and that carried a single copy of the transgene were chosen for further analysis (Supplementary Fig. S2). We evaluated panicle blast resistance and expression levels of $G F 14 b$ at the heading stage in each individual line through the $\mathrm{T}_{3}$ generation. Our results show that enhanced panicle resistance was stably inherited in $\mathrm{T}_{1}$ to $\mathrm{T}_{3}$ generations (Fig. 2A and $\mathrm{B}$; Table 1 ; only $\mathrm{T}_{2}$ generations shown). The enhanced resistance correlated with the increased expression levels of GF14b in all $\mathrm{T}_{1}$ to $\mathrm{T}_{3}$ families (Fig. 2C; Supplementary Fig. $\mathrm{S} 3 \mathrm{~A})$. These results suggest that overexpression of $G F 14 b$ improves resistance against panicle blast.

As a parallel experiment, leaves of the overexpression $G F 14 b \mathrm{~T}_{2}$ transgenic lines (2-1 and 4-4) at the three-and-a-halfleaf stage were inoculated with $M$. oryzae isolate GD08-T13. In contrast to the panicles, leaves of the $\mathrm{T}_{2}$ transgenic plants showed the same susceptibility as the transformed empty-vector control (PHQSN) and the nontransformed control Nipponbare (Fig. 3A; Table 2). Similar results were also obtained in the $\mathrm{T}_{3}$ transgenic plants (Supplementary Fig. S4). This result indicated that overexpression of $G F 14 b$ has no effect on leaf blast resistance.

\section{$G F 14 b$-silenced plants are more susceptible}

to panicle blast but show enhanced resistance to leaf blast.

To further confirm the effects of $G F 14 b$ on blast resistance, we silenced $G F 14 b$ and evaluated blast resistance in the silenced rice plants. Silencing of GF14b expression was achieved by transformation of Nipponbare rice using an RNAi vector containing a 220-bp region from the $3^{\prime}$ untranslated region (UTR) of $G F 14 b$. The 3' UTR sequences of $G F 14 b$ were chosen to specifically silence $G F 14 b$, and not other members of the 14-3-3 gene family. GF14b-suppressed (GF14bRNAi) transgenic plants were phenotypically indistinguishable from untransformed Nipponbare plants. To better distinguish the resistance phenotypes between silenced plants and control plants (PHQSN and Nipponbare), a suspension with a lower concentration of $M$. oryzae spores $\left(5 \times 10^{7}\right.$ spores $\left./ \mathrm{ml}\right)$ was used for inoculations. Fifteen $\mathrm{T}_{0}$ plants with different genesilencing levels were inoculated with the $M$. oryzaae isolate GD08-T13. Expression levels of GF14b and panicle blast resistance in $\mathrm{T}_{0}$ plants were strongly correlated $\left(R^{2}=0.83\right)$ 
(Fig. 3C). Transgenic plants with lower GF14b expression were more susceptible to the blast pathogen (Fig. 3B and D; Table 3). In all, $2 \mathrm{~T}_{0}$ plants (lines 5 and 15), in which GF14b was most highly suppressed, were advanced to the $\mathrm{T}_{1}$ generation, and 20 plants were analyzed for $G F 14 b$ expression. Only 10 plants were silenced, suggesting reduced silencing in the $\mathrm{T}_{1}$ generation (Supplementary Fig. S3B and C), but $G F 14 b$ expression and panicle blast resistance in $\mathrm{T}_{1}$ plants was still highly correlated $\left(R^{2}=0.96\right)$ (Fig. $\left.3 \mathrm{C}\right)$. The $\mathrm{T}_{1}$ transgenic plants with lower expression levels of $G F 14 b$ were more susceptible to the blast pathogen (Fig. 3E; Table 3). These results demonstrate that RNA silencing of $G F 14 b$ makes plants more susceptible to panicle blast.

Leaves of $T_{1}$ plants from $T_{0}$ transgenic lines 5 and 15 were also tested for resistance to leaf blast. After inoculation, leaves were distinguished into two groups: a highly susceptible group that had numerous leaf lesions and a moderately resistant group that had fewer leaf lesions (Fig. 3A; Table 2' only the resistant group is shown). The enhanced resistance of the plants was also correlated with reduced expression levels of $G F 14 b\left(R^{2}=0.89\right)$ (Fig. 3F). These results suggest that $G F 14 b$ negatively regulates leaf blast resistance, a result also observed for $G F 14 e$, the most closely related gene in the 14-3-3 family (Manosalva et al. 2011).

\section{A}

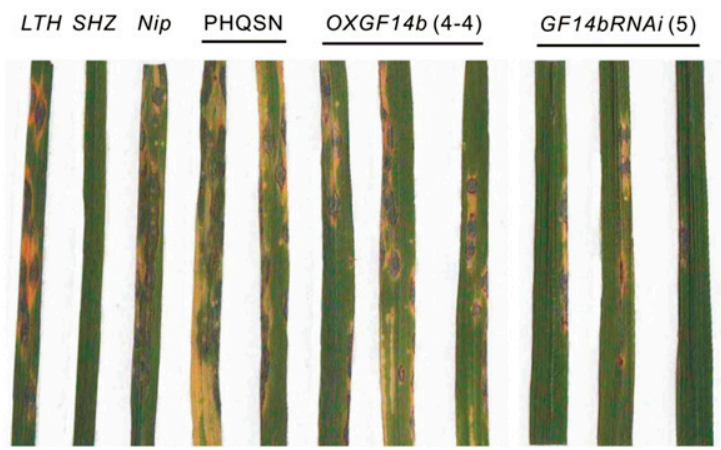

C

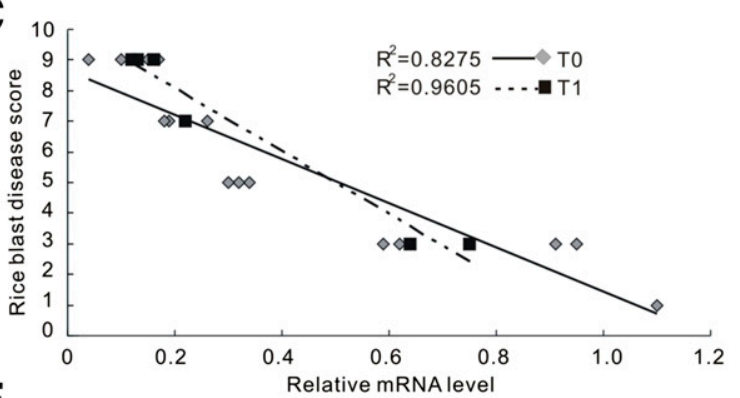

E

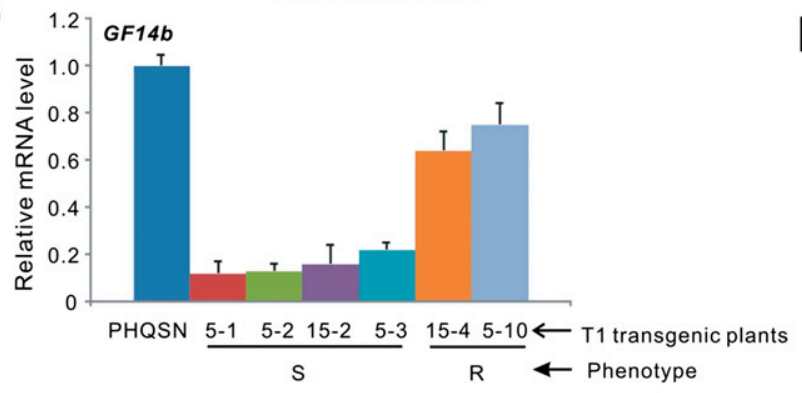

Expression of $G F 14 b$ is regulated by WRKY71.

To identify the regulatory components and understand the mechanisms of $G F 14 b$ in regulation of blast resistance in rice, promoter sequences approximately $1,500 \mathrm{bp}$ from the translational start site of $G F 14 b$ were analyzed for cis elements. In total, $19 \mathrm{~W}$-boxes (TGAC, the binding site for WRKY transcription factors) were observed, 13 of which are putative binding sites for WRKY71 (Supplementary Fig. S5). The numerous binding sites for WRKY71 in the promoter region of

Table 2. Evaluation of leaf blast resistance of $G F 14 b$-overexpressing $\left(\mathrm{OXGF14b)}\right.$ plants and $G F 14 b$-silenced (GF14bRNAi) plants ${ }^{\mathrm{a}}$

\begin{tabular}{lccc}
\hline Line or variety & Total number & Diseased leaf area $(\%)$ & $\boldsymbol{P}$ value \\
\hline PHQSN & 22 & $77.35 \pm 10.84$ & $\ldots$ \\
Nipponbare & 19 & $76.14 \pm 11.85$ & 0.3844 \\
OXGF14b $\left(\mathrm{T}_{2}, 2-1\right)$ & 21 & $74.37 \pm 13.52$ & 0.2446 \\
OXGF14b $\left(\mathrm{T}_{2}, 4-4\right)$ & 22 & $74.35 \pm 14.26$ & 0.2558 \\
GF14bRNAi $\left(\mathrm{T}_{1}, 5\right)$ & 24 & $60 \pm 13.69$ & $0.0037 * * *$ \\
GF14bRNAi $\left(\mathrm{T}_{1}, 15\right)$ & 21 & $55 \pm 11.18$ & $0.0003 * * *$ \\
\hline
\end{tabular}

a Total number $=$ the sum of the inoculated plants at the three-and-a-halfleaf stage. Leaf blast of a given line is scored by measuring the percent diseased leaf area. Each value represents the mean \pm standard error of diseased leaf area. $P$ value is calculated using PHQSN as the control and *** indicates $P<0.001$

B

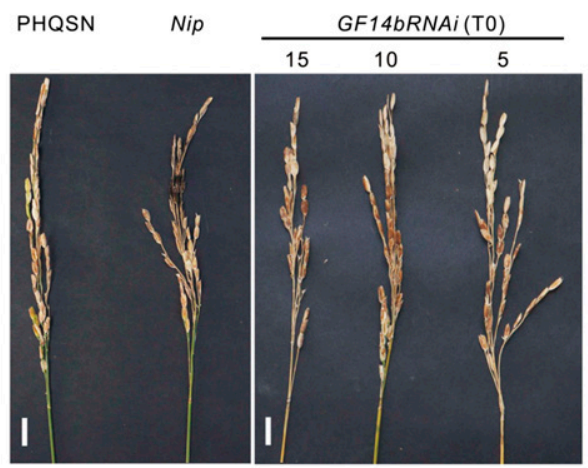

D

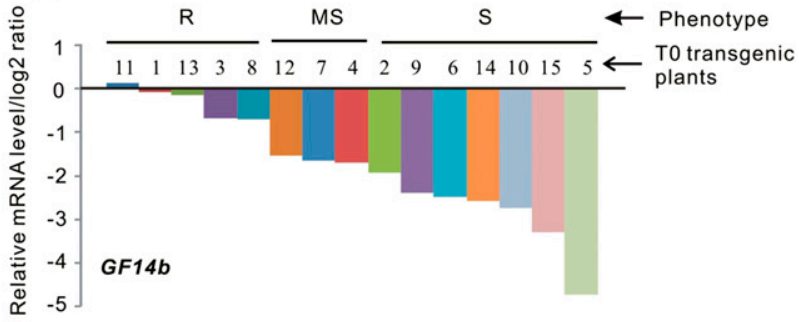

$\mathbf{F}$

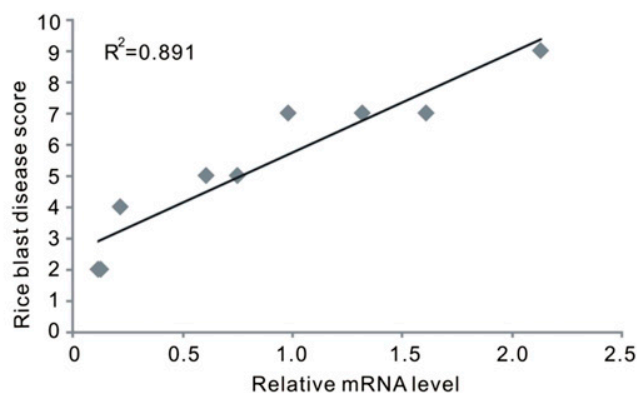

Fig. 3. $G F 14 b$-silenced (GF14bRNAi) plants are resistant to leaf blast infection but susceptible to panicle blast infection. A, $O X G F 14 b$ plants are susceptible to leaf blast but GF14bRNAi plants show enhanced resistance to leaf blast. LTH, which is highly susceptible to rice blast, is the susceptible control and SHZ is blast resistant and is the resistant control. B, GF 14bRNAi plants are susceptible to panicle blast infection. Scale bar $=2 \mathrm{~cm}$. C, Blast disease scores are correlated with the expression levels of $G F 14 b$ in both $\mathrm{T}_{0}$ and $\mathrm{T}_{1}$ transgenic plants after inoculation of panicles with the rice blast fungus. $\mathbf{D}$ and $\mathbf{E}$, Transgenic plants with lower $G F 14 b$ expression levels are more susceptible to panicle blast. F, Blast disease scores were correlated with the expression levels of $G F 14 b$ in $\mathrm{T}_{1}$ gene silencing plants after inoculation of leaves with Magnaporthe oryzae. 
$G F 14 b$ imply that the transcription of $G F 14 b$ may be regulated by WRKY71. To determine whether WRK71 is indeed involved in the regulation of $G F 14 b$, a series of experiments were performed. First, real-time PCR experiments were used to analyze the expression of WRKY71 in ' $\mathrm{BC} 10$ ' rice, a resistant advanced backcross line, after inoculation of leaves and panicles with the blast pathogen. WRKY71 expression was induced during infection of panicles and was significantly suppressed by leaf blast infection at $48 \mathrm{~h}$ after inoculation (Fig. 4A), the same expression pattern as GF14b. Furthermore, WRKY71overexpressing transgenic plants showed enhanced resistance to panicle blast (data not shown). Expression levels of $G F 14 b$ were strongly induced in both $\mathrm{T}_{0}$ and $\mathrm{T}_{1}$ WRKY71-overexpressing plants (Fig. 4B and C; Supplementary Fig. S6A and B). However, overexpression or RNAi suppression of $G F 14 b$ did not cause any change in WRKY71 transcript accumulation (Supplementary Fig. S7). These observations show a parallel relationship between WRKY71 and GF14b in transcript level

Table 3. Evaluation of panicle blast resistance of $G F 14 b$-silenced (GF14bRNAi) plants $\left(\mathrm{T}_{0} \text { and } \mathrm{T}_{1} \text { generation }\right)^{\mathrm{a}}$

\begin{tabular}{lccc}
\hline $\begin{array}{l}\text { Line or } \\
\text { variety }\end{array}$ & $\begin{array}{c}\text { Total } \\
\text { number }\end{array}$ & $\begin{array}{c}\text { Infected main } \\
\text { axis length }(\%)\end{array}$ & $\boldsymbol{P}$ value \\
\hline PHQSN & 5 & $38.21 \pm 2.73$ & $\ldots$ \\
Nipponbare & 6 & $37.14 \pm 4.18$ & 0.4121 \\
GF14bRNAi $\left(\mathrm{T}_{0}\right)$ & 9 & $73.26 \pm 8.66$ & $1.5981 \mathrm{E}-07^{* * *}$ \\
GF14bRNAi $(\mathrm{T} 1,5)$ & 4 & $75 \pm 10$ & $1.0927 \mathrm{E}-05^{* * *}$ \\
GF14bRNAi $(\mathrm{T} 1,15)$ & 3 & $73.33 \pm 11.54$ & $6.5236 \mathrm{E}-05^{* * *}$ \\
\hline
\end{tabular}

a Total number $=$ the sum of the inoculated panicles. The panicle blast resistance of a given line is evaluated by measuring the percent infected main axis length. Percent infected main axis length $=$ infected main axis length/main axis length of the inoculated panicle $\times 100$. Each value represents the mean \pm standard error. $P$ value is calculated using PHQSN as control and *** indicates $P<0.001$. and blast resistance, and suggest that $G F 14 b$ acts downstream of WRKY71.

To determine whether the transcription factor WRKY71 has direct DNA-binding activity to $G F 14 b$, yeast one-hybrid assays were performed using a DNA fragment that contained W-boxes (TGAC) from the promoter region of $G F 14 b$. Another fragment without $\mathrm{W}$ boxes was used as a negative control. These assays demonstrated that WRKY71 possesses specific DNA-binding ability to the promoter of $G F 14 b$ and the promoter sequence without the W-boxes was not recognized by WRKY7l (Fig. 4D). Moreover, WRKY71 was also expressed in Escherichia coli as a fusion protein with His-tag, and an electrophoresis mobility shift assay (EMSA) was conducted with the WRKY71-His fusion protein and the synthesized probes from the promoter region of $G F 14 b$ with two normal or mutant TGAC motifs (Fig. $4 \mathrm{E})$. The WRKY71-His fusion protein bound the probe (14bp) with two normal TGAC motifs, and the binding was abolished by addition of unlabeled competitors (Fig. 4F). In contrast, the WRKY71-His fusion protein did not bind to the probe (m14bp), which has two mutant TGAC motifs (Fig. 4F). Thus, the EMSA confirms the yeast one-hybrid assay and, together, the results are consistent with WRKY71 regulation of Gf14b.

\section{$G F 14 b$ is involved in JA and SA signaling pathways.}

SA and JA are major defense signaling compounds mediating disease resistance in plants (Thaler et al. 2012). To determine whether $G F 14 b$ is involved in SA- and JA-dependent pathways, we analyzed the expression patterns of some well-characterized defense-related genes, including genes related to JA synthesis (the lipoxygenases $L O X 1$ and LOXI1 and an allene oxide synthase 2 [AOS2] gene) and genes related to SA synthesis (the pathogenesis-related $[P R]$ genes $P R I a$ and $P R 10$, an Arabidopsis NPR1 homolog 1 [NHI], and a phenylalanine ammonialyase gene [PAL1]) (Deng et al. 2012). Pathogen infection
A

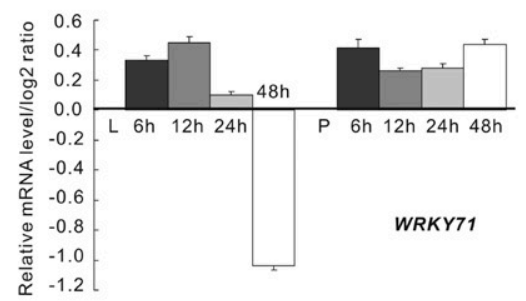

B

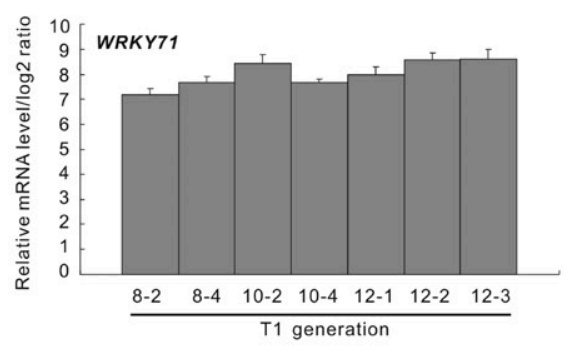

C

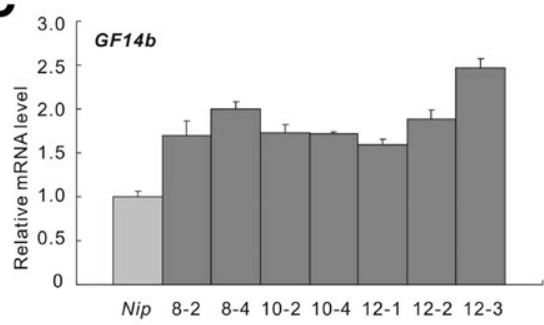

D

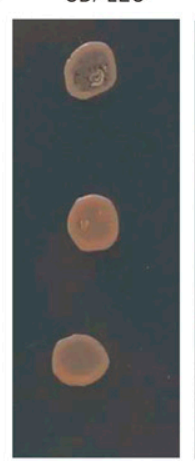

E

14bp: TGCATGACCACTGCGACCTCCGAGCTAGTCTTGACGTGG m14bp: TGCATGAACACTGCGACCTCCGAGCTAGTCTTGAAGTGG

\section{$\mathbf{F}$}

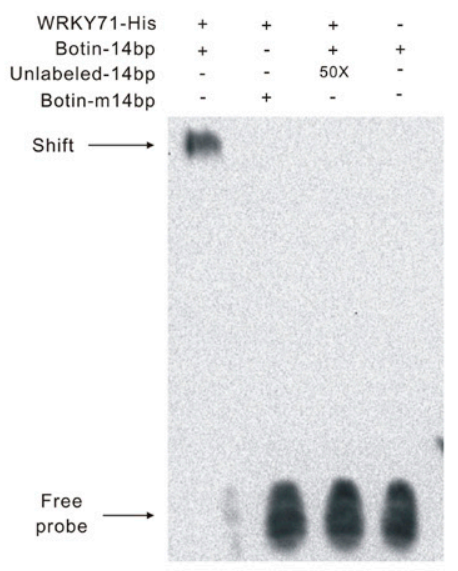

Fig. 4. WRKY71 directly binds to the promoter of $G F 14 b$ to induce its expression. A, Real-time polymerase chain reaction (PCR) showing the response of $W R K Y 71$ to leaf and panicle blast infection. $\mathrm{L}=$ leaf inoculation and $\mathrm{P}=$ panicle inoculation; $6,12,24$, and $48 \mathrm{~h}$ indicates the time after inoculation. $\mathbf{B}, W R K Y 71$ was successfully overexpressed in seven transgenic plants. $\mathbf{C}$, The level of $G F 14 b$ is induced in all the WRKY71-overexpressing plants, as shown by real-time PCR. D, Yeast one-hybrid assay indicates that WRKY71 directly binds to the promoter of $G F 14 b$. E, Oligonucleotides ( $-1,493$ to $-1,454$, from the transcriptional start site of $G F 14 b$ ) used in the electrophoresis mobility shift assay (EMSA). The 14bp probe contains two TGAC sequences and the m14bp probe has two sequences with TGAC mutated to TGAA. The wild-type and mutated sequences are underlined. F, EMSA showing the binding of recombinant WRKY71 to the promoter region of GF14b through the TGAC motif. The oligonucleotides (14bp and m14bp) were used as the probes. Each biotin-labeled DNA probe was incubated with recombinant WRKY71-His protein. An excess of unlabeled probe (Cold-14bp) was added to compete with labeled 14bp probe (Biotin-14bp). Biotin-labeled 14bp probe incubated without WRKY71-His protein served as the negative control. 
strongly induced the expression of $L O X 1, L O X 11$, and AOS2 in both wild-type and $G F 14 b$-overexpressing Nipponbare plants in both leaf and panicle tissue but expression levels of $L O X 1$, $L O X 11$, and AOS2 were significantly higher in GF14b-overexpressing plants than in wild-type plants both before and after pathogen infection (Fig. 5; Supplementary Fig. S8). In contrast, the expression levels of LOX1 and AOS2 were significantly lower in $G F 14 b$-silenced plants than in wild-type plants either before or after M. oryzae infection (Fig. 5). However, the transcript levels of $L O X 11$ were strongly increased in GF14bsilenced plants either before or after infection (Fig. 5). The expression levels of $P A L 1$ were significantly lower in $G F 14 b$ overexpressing plants in both leaf and panicle tissue and significantly higher in $G F 14 b$-silenced plants than in the corresponding wild-type plants before and after blast infection (Fig. 5). There were no obvious differences in expression levels of PRIa, PR1O, and NHI between transgenic plants and wild-type plants either before or after blast pathogen inoculation (data not shown).

To further confirm whether $G F 14 b$ is involved in JA and SA signaling pathways, the wild-type Nipponbare and GF14boverexpressing plants were treated with JA and SA and the expression levels of $G F 14 b$ in these plants were analyzed at both the seedling and heading stage. We also examined, in parallel, the expression of the JA-related genes ( $L O X 1, L O X 11$, and $A O S 2$ ) and SA-related gene PAL1 in Nipponbare. Our results show that JA significantly induced the expression of
$L O X 1, L O X 11$, and AOS2 and that PAL1 was rapidly induced with a maximal transcript accumulation at $6 \mathrm{~h}$ after SA treatment (Supplementary Fig. S9). In accordance with the previous study (Chen et al. 2006), GF14b was significantly repressed at $3 \mathrm{~h}$ after JA treatment in Nipponbare but its expression returned to baseline levels at 6 and $12 \mathrm{~h}$, and then was slightly induced at $24 \mathrm{~h}$ after treatment at the seedling stage (Fig. 6A). Similar to the result in JA treatment, $G F 14 b$ expression was repressed at 3 and $6 \mathrm{~h}$ then induced at $24 \mathrm{~h}$ after SA treatment at the seedling stage (Fig. 6A). However, its expression was significantly induced by exogenous addition of both JA and SA at the heading stage (Fig. 6C).With regard to the GF14b-overexpressing plants, both exogenous JA and SA treatment strongly induced expression of $G F 14 b$ at all time points after pathogen inoculation at both the seedling and heading stage (Fig. 6B and D). Taken together, these results suggest that $G F 14 b$ positively regulates the JA-dependent pathway while negatively regulating the SA-dependent pathway.

\section{DISCUSSION}

\section{$G F 14 b$ plays opposite roles}

in panicle blast resistance and leaf blast resistance.

Although 14-3-3 proteins function as regulators in a variety of physiological processes (Gökirmak et al. 2010; Oecking and Jaspert 2009; Purwestri et al. 2009; Roberts 2003; Shin et al. 2011; Yao et al. 2007), little is known about their roles in rice
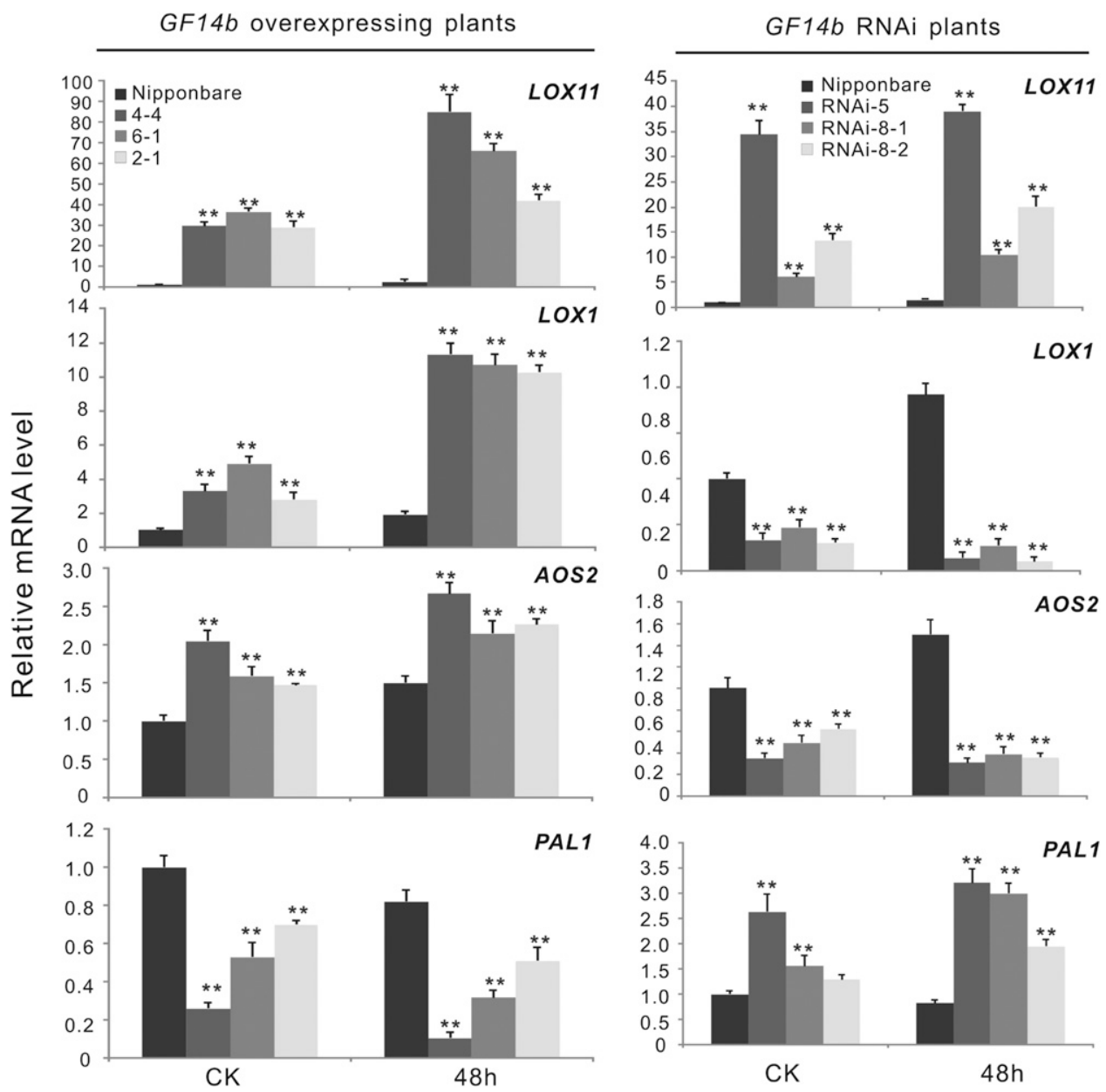

Fig. 5. Transcriptionally modulated $G F 14 b$ influenced the expression of a set of defense responsive genes. Transgenic and wild-type plants were inoculated with Magnaporthe oryzae isolate GD08-T13 at the heading stage, and relative gene expression was measured by real-time quantitative polymerase chain reaction. Asterisks indicate significant differences between transgenic and wild-type plants before blast infection (CK) and at $48 \mathrm{~h}$ after infection with $M$. oryzae at $P<0.01$. Expression data are the means of three replicates \pm standard deviation. 
blast disease or resistance, particularly in panicle blast, the more destructive type of rice blast disease. Though previous studies showed that GF14e was colocalized with a QTL for blast resistance (Liu et al.2004), and GF14b, GF14c, GF14e, and $G F 14 f$ are differentially expressed in rice seedlings after challenge by blast pathogen (Chen et al. 2006), only GF14e has been confirmed to function in leaf blast resistance (Manosalva et al. 2011). In the present study, the $G F 14 b$-overexpressing plants showed enhanced resistance to panicle blast (Fig. 2A) but were susceptible to leaf blast (Fig. 3A). In contrast, RNAi silencing of $G F 14 b$ led to increased susceptibility to panicle blast (Fig. 3B) but enhanced leaf blast (Fig. 3A). Interestingly, $G F 14 b$ showed a dynamic expression pattern, with increased transcript levels from the booting stage to the heading stage (Fig. 1B and 1C). The higher expression level of GF14b at heading stage is consistent with its role in panicle blast resistance, because panicle blast normally occurs after heading in rice. Overall, we demonstrate the involvement of the 14-3-3 protein family in panicle blast resistance, and show that one family member, $G F 14 b$, functions as a positive regulator of panicle blast but a negative regulator of leaf blast resistance. This study provides new, compelling evidence for the difference in mechanisms between leaf and panicle blast resistance in rice.

\section{WRKY genes are involved}

in $G F 14 b$-mediated rice blast resistance.

The WRKY superfamily, which is localized in the nucleus, regulates gene expression by binding to the $\mathrm{W}$-boxes in the promoter regions of the target genes (Eulgem et al. 2000). Thus far, many $W R K Y$ genes have been reported to be involved in disease resistance in different plants (Journot-Catalino et al. 2006; Kim et al. 2006; Marchive et al. 2013; Meng and Wise 2012; Wang et al. 2013; Yu et al. 2012), including rice (Chujo et al. 2013; Liu et al. 2007; Peng et al. 2010; Qiu et al. 2007; Wei et al. 2013). The presence of $19 \mathrm{~W}$-boxes (including 13 binding sites of $W R K Y 71$ ) in the promoter region of $G F 14 b$, the localization of $G F 14 b$ to the nucleus (Chen et al. 2006), the similar expression patterns of OsWRKY71 and GF14b during leaf and panicle blast infection (Fig. 4A), and our evidence that OsWRKY71 binds to the promoter of GF14b (Fig. 4D and F) are consistent with the regulation of $G F 14 b$ by $W R K Y$ genes, particularly the $O s W R K Y 71$. Strong induction of $G F 14 \mathrm{~b}$ in both $\mathrm{T}_{0}$ and $\mathrm{T}_{1}$ OsWRKY71-overexpressing plants (Fig. $4 \mathrm{~B}$ and $\mathrm{C}$ ) further supports a role for OsWRKY71 in regulation of $G F 14 b$. Because overexpression or RNAi suppression of $G F 14 b$ did not cause any change in $O s W R K Y 71$ transcript accumulation, we propose that $O s W R K Y 71$ controls $G F 14 b$-mediated resistance to $M$. oryzae in rice by regulating the transcription of $G F 14 b$ but that $G F 14 b$ acts downstream of WRKY71. However, there are numerous W-boxes in the promoter regions of $G F 14 b$ and our microarray experiments also showed that several $W R K Y$ genes, in addition to $O S W R K Y 71$, were differentially expressed during leaf and panicle blast infection (data not shown). Therefore, it is possible that other $W R K Y$ genes may be also involved in regulating the transcription of $G F 14 b$. Further study will be required to confirm the interactions between other $W R K Y$ genes and GF14b.

\section{$G F 14 b$-mediated disease resistance is associated with activation of the JA-dependent pathway and suppression of $\mathrm{SA}$-dependent pathway.}

The 14-3-3 proteins function as regulators of a wide range of target proteins by regulating target proteins that function in either transcriptional activation or defense (Roberts et al. 2002). $G F 14 e$-silenced rice plants showed enhanced resistance to a virulent strain of $X$. oryzae pv. oryzae and the necrotrophic fungal pathogen Rhizoctonia solani, and the enhanced resistance was correlated with higher basal expression of a DR peroxidase gene ( $P O X 22.3)$ and accumulation of reactive oxygen species (ROS) (Manosalva et al. 2011). Among the eight members in the 14-3-3 gene family, $G F 14 b$ is most closely related to GF14e (Chen et al. 2006). Thus, it is reasonable to expect that they might have similar functions and mechanisms in disease resistance in rice. Indeed, both $G F 14 e$ and GF14b function as negative regulators in leaf blast resistance. However, the levels of ROS in the GF14b-overexpressing plants and the $G F 14 b$-silenced plants were not significantly changed
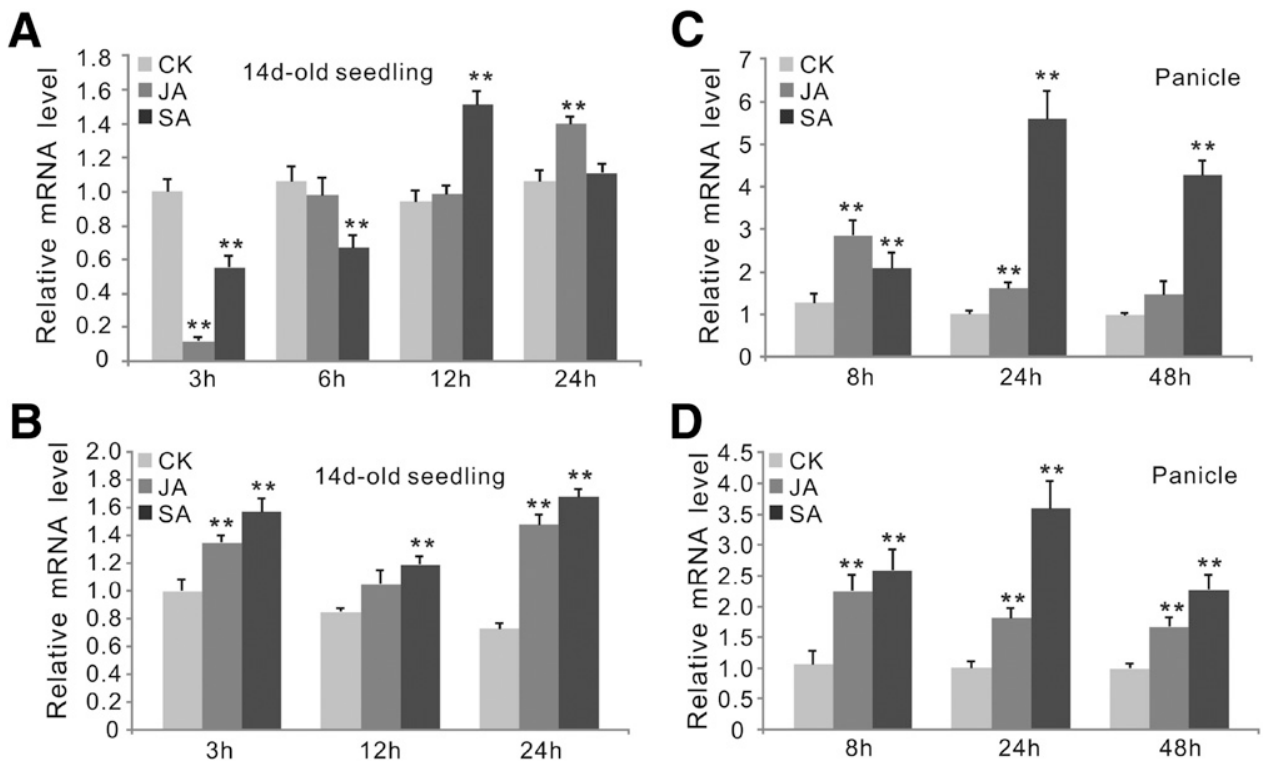

Fig. 6. Effects of jasmonic acid (JA) and salicylic acid (SA) on the expression of $G F 14 b$. A, Exogenously applied JA and SA affect the expression of $G F 14 b$ in Nipponbare rice at the seedling stage. B, Exogenously applied JA and SA strongly induce the expression of $G F 14 b$ at 3,12 , and $24 \mathrm{~h}$ after treatment in the $O X G F 14 b$ overexpression plants at the seedling stage. C, Exogenously applied JA and SA affect the expression of $G F 14 b$ in panicle tissue of Nipponbare. D, Exogenously applied JA and SA strongly induce the expression of $G F 14 b$ at 8,24 , and 48 h after treatment in panicle tissue of $O X G F 14 b$ overexpression plants. Asterisks indicate a significant difference between the control $(\mathrm{CK})$ and hormone treatments at the same time, with $P<0.01$. Expression data are the mean of three replicates \pm standard deviation. 
compared with wild-type plants (data not shown), suggesting that $G F 14 b$-mediated blast resistance is independent of the ROS signaling pathway and there may be different pathogen response pathways among the members in 14-3-3 gene family.

The signaling molecule JA has been implicated in the regulation of many plant resistance responses (Robert-Seilaniantz et al. 2011). The JA synthesis pathway originates from $\alpha$-linolenic acid, and $L O X$ and $A O S 2$ encode two important enzymes in this pathway (Xie et al. 2011; Zhao et al. 2005). $L O X$, which catalyzes the first step in biosynthesis of JA from $\alpha$-linolenic acid, plays a pivotal role in rice resistance to blast fungus (Ohta et al. 1991; Peng et al. 1994; Qiu et al. 2007). Additionally, overexpression of AOS 2 increases endogenous JA and enhances resistance to blast in rice (Mei et al. 2006). In the present study, we observed that the expression levels of $L O X 1$, $L O X 11$, and $A O S 2$ were higher in the $G F 14 b$-overexpressing plants than in wild-type (Nipponbare) plants both before and after blast infection (Fig. 5), consistent with a more active JA signaling pathway in $G F 14 b$-overexpressing plants. In contrast, the expression of the LOX1 and AOS 2 genes were more reduced in $G F 14 b$-silenced plants than in Nipponbare both before and after infection (Fig. 5), likely leading to reduced JA signaling in $G F 14 b$ silencing plants. Exogenous JA induced the accumulation of $G F 14 b$ in both Nipponbare and the $G F 14 b$ overexpressing plants (Fig. 6), and the accumulation of $G F 14 b$ occurs more rapidly in the $G F 14 b$-overexpressing plants than in Nipponbare. These results suggest that $G F 14 b$ positively regulates the JA-dependent pathway. Thus, one possible role for $G F 14 b$ in defense against rice blast may be as a positive regulator of JA-mediated DR signaling.

SA is another plant hormone involved in host-pathogen interactions. In the present study, we analyzed the expression of PRIa, PR10, NH1, and PAL1 genes, which are associated with SA-dependent pathways. Only the expression of $P A L 1$ was significantly suppressed in $G F 14 b$-overexpressing plants whereas its expression was strongly induced in $G F 14 b$-silenced plants both before and after inoculation (Fig. 5). PAL1 is a member of the phenyalanine ammonia lyase gene family, which encodes enzymes that catalyze the first step in the phenylpropanoid pathway and, ultimately, in SA biosynthesis (Olsen et al. 2008). These results suggest that $G F 14 b$ might play a negative role in SA-mediated signaling pathways through negative regulation of SA biosynthesis. Application of exogenous SA strongly induced the accumulation of $G F 14 b$ in both wild-type and GF $14 b$-overexpressing plants (Fig. 6). Thus, one action site of $G F 14 b$ should be downstream of SA and upstream of PAL1 in the defense signaling network. Both SA and JA can induce the expression of $G F 14 b$. However, the expression patterns of defense-related genes involved in the biosynthesis of JA and SA in transgenic plants clearly indicated that GF14b activates the JA-dependent pathway and suppresses the SAdependent pathway. Hence, our data indicate that GF14b may be involved in antagonistic interactions between SA- and JAdependent pathways, perhaps by regulating the expression of a subset of genes involved in synthesis of SA and JA, through multiple positive and negative feedback loops. The antagonistic interactions between JA-dependent and SA-dependent DR pathways have been described in studies of disease responses involving many $D R$ genes such as WRKY70 (Li et al. 2004), WRKY33 (Zheng et al. 2006), and C3H12 (Deng et al. 2012). Nevertheless, the molecular mechanisms underlying these antagonistic interactions remain unclear. Regulatory proteins such as GF14b may provide tools to further elucidate the mechanisms of the antagonistic actions between different DR pathways.

Expression of LOX11 significantly increased in the GF14boverexpressing plants relative to wild-type plants before and after infection (Fig. 5). However, LOX11 was also significantly induced in the $G F 14 b$-silenced plants compared with wild-type plants before and after inoculation. These results indicate that one or more other factors independent of $G F 14 b$ also regulate some $D R$ genes. These results also suggest that multiple mechanisms may be involved in rice resistance against $M$. oryzae.

In conclusion, in the present study, we have confirmed the functions of $G F 14 b$ on leaf and panicle blast resistance by differential expression and transgenic method and investigated its possible regulatory mechanism. Our results suggest that GF $14 b$ positively regulates panicle blast resistance while negatively modulating leaf blast resistance (Fig. 7). OsWRKY71 controls $G F 14 b$-mediated resistance to $M$. oryzae in rice by regulating the transcription of $G F 14 b$, and $G F 14 b$-mediated disease resistance is associated with activation of the JAdependent pathway and suppression of the SA-dependent pathway. However, because there are numerous W-boxes in the promoter region of $G F 14 b$, we do not know whether other $W R K Y$ factors in addition to OsWRKY71 are involved in $G F 14 b$-mediated resistance to $M$. oryzae in rice. Furthermore, we still do not know whether the other 14-3-3 genes also play different roles in leaf and panicle blast resistance and how GF14b coordinates with the other 14-3-3 genes to contribute to blast resistance in rice. Further study is needed to address these issues. Our results provide new insight into the functions of the 14-3-3 gene family in blast resistance in rice, and the demonstration of different functions of $G F 14 b$ in leaf and panicle blast resistance provides new, compelling evidence for the difference in mechanisms between leaf and panicle blast resistance in rice which may, in part, account for the low correlation between the levels of leaf and panicle blast observed in the field.

\section{MATERIALS AND METHODS}

\section{Vector constructs and rice transformation.}

For the $P_{35 s}: G F 14 b(O X G F 14 b)$ construct, GF14b cDNA was amplified from $\mathrm{BC} 10$ rice, a blast-resistant line, by realtime PCR using forward primer 5'-TGCAGACTTGGCATTTG TAGAG-3' and reverse primer 5'-TACGAGTAGCTTAAAGG CGAGA-3'. The GF14b RNAi construct was generated by cloning an antisense 219-bp PCR product corresponding to the 3' UTR of GF14b. This fragment was amplified using forward primer 5'-ACCTATGTGGCTGTGATTGTTG-3' and reverse primer 5'-CGGACCATAACAATAAACACCAAT-3'. The resulting products were cloned into pEASY-T1 (TransGen) and verified by sequencing. The entry clone for $O X G F 14 b$ was inserted into pHQSN (modified from pCAMBIA1390), harboring

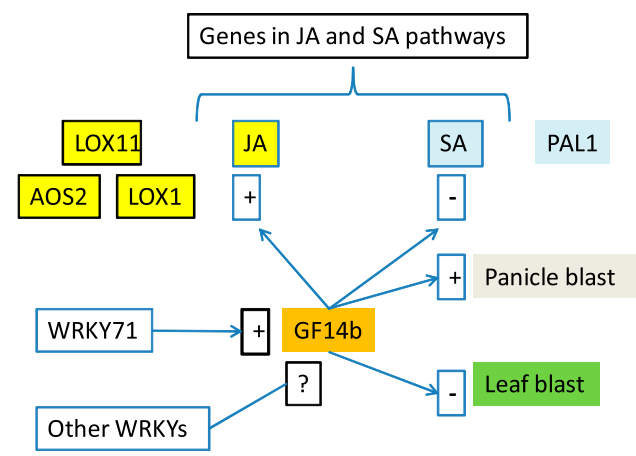

Fig. 7. Diagram proposing the effects of $G F 14 b$ on leaf and panicle blast resistance in rice and its possible regulatory mechanism. $L O X 1, L O X 2$, and $A O S 2$ are the key genes in the jasmonic acid (JA) pathway; PAL1 is a key gene in the salicylic acid (SA) pathway; $+=$ positive regulation, $-=$ negative regulation, and $?=$ unknown. 
a Cauliflower mosaic virus $35 \mathrm{~S}$ promoter. The clone for silencing was inserted into pRNAi-Ubi, which is suitable for generation of hairpin-RNA constructs. The overexpression construct of WRKY71 was made by inserting the coding sequence into pHQSN using the same method.

The $P_{G F 14 b}: G U S$ constructs were produced as follows: approximately $2.0-\mathrm{kb}$ fragments were amplified from upstream of $G F 14 b$ in BC10 genomic DNA using specific primers $\left(5^{\prime}-\right.$ GCACTGGTTTCAATAGTTCGGG-3' and 5'-GCGAAGGAA TACCTCTGTGTGC-3'). The fragment was subcloned into pCAMBIA1381Z with GUS. All plasmids were electroporated into Agrobacterium tumefaciens EHA105. The expression and control vectors were introduced into calli of Nipponbare via Agrobacterium-mediated genetic transformation.

\section{Real-time quantification of mRNA.}

Total RNA was extracted using TRIzol reagent (Invitrogen) according to the manufacturer's instructions. Total RNA was reverse-transcribed using the Primescript RT reagent kit (Takara). Real-time PCR was carried out using SYBR Premix ExTaq (Takara) to detect PCR products. The EFl $\alpha$ gene was used as a reference gene. Real-time PCR was performed according to the manufacturer's instructions, and the resulting melting curves were visually inspected to ensure specificity of product detection. Gene expression was quantified by the comparative cycle threshold method. Experiments were performed in triplicate, and results were represented as mean \pm standard deviation. The primers used in this study are listed in Supplementary Table S1.

\section{Plant growth and pathogen inoculations.}

$\mathrm{T}_{0}$ transgenic plants generated from calli were transferred to soil; these and the $T_{1}, T_{2}$, and $T_{3}$ segregating progeny germinated from seed were grown in soil in the greenhouse. For evaluation of leaf blast resistance, seedlings were inoculated at 14 days after sowing by spraying with spore suspension of M. oryzae isolate GD08-T13 at $1 \times 10^{6}$ spores $/ \mathrm{ml}$. Inoculated plants were maintained in a growth chamber $\left(25^{\circ} \mathrm{C}, 16,000\right.$ Lux, and $100 \%$ relative humidity) in the dark for $24 \mathrm{~h}$; then, the growth chamber was set to a photoperiod of $16 \mathrm{~h}$ of light and $8 \mathrm{~h}$ of darkness at $25^{\circ} \mathrm{C}$ and $100 \%$ relative humidity. Disease was assessed 5 days after inoculation by measuring the percent DLA. Each treatment was repeated twice. For panicle blast inoculation, a cotton-wrapping inoculation method was used. The upper-middle part of a panicle was wrapped with sterile cotton at 2 to 3 days after heading. Next, $1 \mathrm{ml}$ of a suspension of M. oryzae GD08-T13 at $1 \times 10^{7}$ spores $/ \mathrm{ml}$ was injected into the cotton, after which the cotton was wrapped with foil. The inoculated plants were sprayed with water for 3 to 4 min every $3 \mathrm{~h}$ to maintain the humidity. Evaluation of panicle blast resistance was conducted at 3 weeks after inoculation by measuring the percent infected main axis length.

\section{Promoter analysis for $c$ is elements.}

Approximately $1,500 \mathrm{bp}$ of sequence upstream of the $G F 14 \mathrm{~b}$ coding region was extracted from the MSU rice genome annotation project to identify cis-acting elements. The sequence was scanned by PLACE, a database that includes nucleotide sequence motifs found in plant cis-acting regulatory DNA elements.

\section{Yeast one-hybrid assays.}

The interaction of WRKY71 protein with W-boxes in the promoter region of $G F 14 b$ was examined using a yeast onehybrid assay according to the manufacturer's protocol (Clontech Yeast Protocols Handbook; BD Biosciences Clontech). The DNA fragment without a W-box from the promoter region of
GF $14 b$ was used as a negative control. Positive interactions were verified by growing on SD-Leu agar medium with Aureobasidin A added.

\section{GUS activity histochemical staining.}

GUS activity in transgenic seedlings was localized by histochemical staining with 5-bromo-4-chloro-3-indolyl- $\beta$-Dglucuronic acid (X-Gluc). Transgenic seedlings were incubated overnight at $37^{\circ} \mathrm{C}$ in staining buffer ( $1 \mathrm{mM}$ X-Gluc, $100 \mathrm{mM}$ sodium phosphate [pH 7.0], $10 \mathrm{mM}$ EDTA, $0.5 \mathrm{mM} \mathrm{K} \mathrm{K}_{4} \mathrm{Fe}$ $(\mathrm{CN})_{6}, 0.5 \mathrm{~mm} \mathrm{~K}_{3} \mathrm{Fe}(\mathrm{CN})_{6}$, and $0.1 \%$ [vol/vol] Triton X-100) and then destained in $70 \%$ ethanol before photography.

\section{EMSA.}

For generation of recombinant WRKY71 proteins, its fulllength cDNA clone was cloned into pET32a (Novagen) and transformed into Escherichia coli strain BL21(DE3)plysS. Induction of expression and purification of recombinant Histagged WRKY71 proteins were performed according to the protocol provided by Novagen. The purified proteins were then refolded according to the Pierce Protein Refolding kit. The EMSA experiments were conducted using a LightShift Chemiluminescent EMSA Kit (Pierce) following the manufacturer's protocol. The fragments of the $G F 14 b$ promoters were synthesized by Sangon (Shanghai) and were biotin labeled. Biotin-unlabeled fragments of the same sequences were used as competitors.

\section{Phytohormone treatments.}

Mature seed of Nipponbare and transgenic plants were soaked in distilled water for 2 days at room temperature. Then, the seed were placed in sterile gauze for another 1 day at room temperature for germination. Germinated seed were placed in gauze and transferred to a tray for incubation in a growth chamber at $25^{\circ} \mathrm{C}, 16,000 \mathrm{Lux}, 70 \%$ relative humidity, and a $12-\mathrm{h}$ photoperiod. Two-week-old rice seedlings were sprinkled with different plant hormone solutions, each at a concentration of $100 \mu \mathrm{M}$. Sampling for RNA extraction was conducted at 3, 6, 12, and $24 \mathrm{~h}$ after treatment. For hormone treatment on the panicle tissue, the same cotton-wrapping inoculation method was used as the pathogen inoculation. Sampling for RNA extraction was conducted at 8,24 , and $48 \mathrm{~h}$ after treatment. The experiments were repeated twice.

\section{ACKNOWLEDGMENTS}

This research was supported partially by NSFC-IRRI project (31461143019), the 973 project of Ministry of Science and Technology, China (2006BFD33320), the National Natural Science Foundation of China (30771392), and the Presidential Foundation of the Guangdong Academy of Agricultural Sciences, China (201201).

\section{LITERATURE CITED}

Ballini, E., Morel, J. B., Droc, G., Price, A., Courtois, B., Notteghem, J. L., and Tharreau, D. 2008. A genome-wide meta-analysis of rice blast resistance genes and quantitative trait loci provides new insights into partial and complete resistance. Mol. Plant-Microbe Interact. 21:859868.

Chen, F., Li, Q., Sun, L., and He, Z. 2006. The rice 14-3-3 gene family and its involvement in responses to biotic and abiotic stress. DNA Res. 13: 53-63.

Chujo, T., Miyamoto, K., Shimogawa, T., Shimizu, T., Otake, Y., Yokotani, N., Nishizawa, Y., Shibuya, N., Nojiri, H., Yamane, H., Minami, E., and Okada, K. 2013. OsWRKY28, a PAMP-responsive transrepressor, negatively regulates innate immune responses in rice against rice blast fungus. Plant Mol. Biol. 82:23-37.

Cooper, B., Clarke, J. D., Budworth, P., Kreps, J., Hutchison, D., Park, S., Guimil, S., Dunn, M., Luginbühl, P., Ellero, C., Goff, S. A., and Glazebrook, J. 2003. A network of rice genes associated with stress 
response and seed development. Proc. Natl. Acad. Sci. U.S.A. 100:49454950.

Dai, L.-Y., Liu, X.-L., Xiao, Y.-H., and Wang, G.-L. 2007. Recent advances in cloning and characterization of disease resistance genes in rice. J. Integr. Plant Biol. 49:112-119.

Deng, H., Liu, H., Li, X., Xiao, J., and Wang, S. 2012. A CCCH-type zinc finger nucleic acid-binding protein quantitatively confers resistance against rice bacterial blight disease. Plant Physiol. 158:876-889.

Dodds, P. N., and Rathjen, J. P. 2010. Plant immunity: Towards an integrated view of plant-pathogen interactions. Nat. Rev. Genet. 11: 539-548.

Eulgem, T., Rushton, P. J., Robatzek, S., and Somssich, I. E. 2000. The WRKY superfamily of plant transcription factors. Trends Plant Sci. 5:199-206.

Finnie, C., Andersen, C. H., Borch, J., Gjetting, S., Christensen, A. B., de Boer, A. H., Thordal-Christensen, H., and Collinge, D. B. 2002. Do 14-3-3 proteins and plasma membrane $\mathrm{H}+$-AtPases interact in the barley epidermis in response to the barley powdery mildew fungus? Plant Mol. Biol. 49:137-147.

Fu, D., Uauy, C., Distelfeld, A., Blechl, A., Epstein, L., Chen, X., Sela, H., Fahima, T., and Dubcovsky, J. 2009. A kinase-START gene confers temperature-dependent resistance to wheat stripe rust. Science 323:13571360.

Fu, J., Liu, H., Li, Y., Yu, H., Li, X., Xiao, J., and Wang, S. 2011. Manipulating broad-spectrum disease resistance by suppressing pathogen-induced auxin accumulation in rice. Plant Physiol. 155:589-602.

Fukuoka, S., Saka, N., Koga, H., Ono, K., Shimizu, T., Ebana, K., Hayashi, N., Takahashi, A., Hirochika, H., Okuno, K., and Yano, M. 2009. Loss of function of a proline-containing protein confers durable disease resistance in rice. Science 325:998-1001.

Gökirmak, T., Paul, A. L., and Ferl, R. J. 2010. Plant phosphopeptidebinding proteins as signaling mediators. Curr. Opin. Plant Biol. 13: 527-532.

Hu, K. M., Qiu, D. Y., Shen, X. L., Li, X. H., and Wang, S. P. 2008. Isolation and manipulation of quantitative trait loci for disease resistance in rice using a candidate gene approach. Mol. Plant 1:786-793.

Jones, J. D., and Dangl, J. L. 2006. The plant immune system. Nature 444: 323-329.

Journot-Catalino, N., Somssich, I. E., Roby, D., and Kroj, T. 2006. The transcription factors WRKY11 and WRKY17 act as negative regulators of basal resistance in Arabidopsis thaliana. Plant Cell 18:3289-3302.

Kim, K. C., Fan, B., and Chen, Z. 2006. Pathogen-induced Arabidopsis WRKY7 is a transcriptional repressor and enhances plant susceptibility to Pseudomonas syringae. Plant Physiol. 142:1180-1192.

Kou, Y., and Wang, S. 2010. Broad-spectrum and durability: Understanding of quantitative disease resistance. Curr. Opin. Plant Biol. 13:181-185.

Li, J., Brader, G., and Palva, E. T. 2004. The WRKY70 transcription factor: A node of convergence for jasmonate-mediated and salicylate-mediated signals in plant defense. Plant Cell 16:319-331.

Liu, B., Zhang, S., Zhu, X., Yang, Q., Wu, S., Mei, M., Mauleon, R., Leach, J., Mew, T., and Leung, H. 2004. Candidate defense genes as predictors of quantitative blast resistance in rice. Mol. Plant-Microbe Interact. 17: 1146-1152.

Liu, W., Liu, J., Ning, Y., Ding, B., Wang, X., Wang, Z., and Wang, G. L. 2013. Recent progress in understanding PAMP- and effector-triggered immunity against the rice blast fungus Magnaporthe oryzae. Mol. Plant 6:605-620.

Liu, X., Bai, X., Wang, X., and Chu, C. 2007. OsWRKY71, a rice transcription factor, is involved in rice defense response. J. Plant Physiol. 164: 969-979.

Manosalva, P., Davidson, R., Liu, B., Zhu, X., Hulbert, S., Leung, H., and Leach, J. 2009. A germin-like protein gene family functions as a complex QTL conferring broad-spectrum disease resistance in rice. Plant Physiol. 149:286-296.

Manosalva, P. M., Bruce, M., and Leach, J. E. 2011. Rice 14-3-3 protein (GF14e) negatively affects cell death and disease resistance. Plant J. 68: 777-787.

Marchive, C., Léon, C., Kappel, C., Coutos-Thévenot, P., Corio-Costet, M. F., Delrot, S., and Lauvergeat, V. 2013. Over-expression of VvWRKY1 in grapevines induces expression of jasmonic acid pathway-related genes and confers higher tolerance to the downy mildew. PLoS One 8: e54185.

McDonald, B. A., and Linde, C. 2002. Pathogen population genetics, evolutionary potential, and durable resistance. Annu. Rev. Phytopathol. 40:349-379.

Mei, C., Qi, M., Sheng, G., and Yang, Y. 2006. Inducible overexpression of a rice allene oxide synthase gene increases the endogenous jasmonic acid level, PR gene expression, and host resistance to fungal infection. Mol. Plant-Microbe Interact. 19:1127-1137.
Meng, Y., and Wise, R. P. 2012. HvWRKY10, HvWRKY19, and HvWRKY28 regulate Mla-triggered immunity and basal defense to barley powdery mildew. Mol. Plant-Microbe Interact. 25:1492-1505.

Oecking, C., and Jaspert, N. 2009. Plant 14-3-3 proteins catch up with their mammalian orthologs. Curr. Opin. Plant Biol. 12:760-765.

Oh, C. S., Pedley, K. F., and Martin, G. B. 2010. Tomato 14-3-3 protein 7 positively regulates immunity-associated programmed cell death by enhancing protein abundance and signaling ability of MAPKKK alpha. Plant Cell 22:260-272.

Ohta, H., Shida, K., Peng, Y. L., Furusawa, I., Shishiyama, J., Aibara, S., and Morita, Y. 1991. A lipoxygenase pathway is activated in rice after infection with the rice blast fungus Magnaporthe grisea. Plant Physiol 97:94-98.

Olsen, K. M., Lea, U. S., Slimestad, R., Verheul, M., and Lillo, C. 2008. Differential expression of four Arabidopsis PAL genes; PAL1 and PAL2 have functional specialization in abiotic environmental-triggered flavonoid synthesis. J. Plant Physiol. 165:1491-1499.

Peng, Y., Bartley, L. E., Canlas, P., and Ronald, P. C. 2010. OsWRKY IIa transcription factors modulate rice innate immunity. Rice 3:36-42.

Peng, Y. L., Shirano, Y., Ohta, H., Hibino, T., Tanaka, K., and Shibata, D. 1994. A novel lipoxygenase from rice. Primary structure and specific expression upon incompatible infection with rice blast fungus. J. Biol Chem. 269:3755-3761

Purwestri, Y. A., Ogaki, Y., Tamaki, S., Tsuji, H., and Shimamoto, K. 2009. The 14-3-3 protein GF14c acts as a negative regulator of flowering in rice by interacting with the florigen Hd3a. Plant Cell Physiol. 50:429438.

Qiu, D., Xiao, J., Ding, X., Xiong, M., Cai, M., Cao, Y., Li, X., Xu, C., and Wang, S. 2007. OsWRKY13 mediates rice disease resistance by regulating defense-related genes in salicylate- and jasmonate-dependent signaling. Mol. Plant-Microbe Interact. 20:492-499.

Ramalingam, J., Vera Cruz, C. M., Kukreja, K., Chittoor, J. M., Wu, J. L., Lee, S. W., Baraoidan, M., George, M. L., Cohen, M. B., Hulbert, S. H., Leach, J. E., and Leung, H. 2003. Candidate defense genes from rice, barley, and maize and their association with qualitative and quantitative resistance in rice. Mol. Plant-Microbe Interact. 16:14-24.

Robert-Seilaniantz, A., Grant, M., and Jones, J. D. 2011. Hormone crosstalk in plant disease and defense: More than just jasmonate-salicylate antagonism. Annu. Rev. Phytopathol. 49:317-343.

Roberts, M. R. 2003. 14-3-3 proteins find new partners in plant cell signalling. Trends Plant Sci. 8:218-223.

Roberts, M. R., Salinas, J., and Collinge, D. B. 2002. 14-3-3 proteins and the response to abiotic and biotic stress. Plant Mol. Biol. 50:1031-1039.

Rosenquist, M., Sehnke, P., Ferl, R. J., Sommarin, M., and Larsson, C. 2000. Evolution of the 14-3-3 protein family: Does the large number of isoforms in multicellular organisms reflect functional specificity? J. Mol. Evol. 51:446-458.

Shin, R., Jez, J. M., Basra, A., Zhang, B., and Schachtman, D. P. 2011.14 3-3 proteins fine-tune plant nutrient metabolism. FEBS (Fed. Eur. Biochem. Soc.) Lett. 585:143-147.

Thaler, J. S., Humphrey, P. T., and Whiteman, N. K. 2012. Evolution of jasmonate and salicylate signal crosstalk. Trends Plant Sci. 17:260-270.

Wang, Y., Dang, F., Liu, Z., Wang, X., Eulgem, T., Lai, Y., Yu, L., She, J., Shi, Y., Lin, J., Chen, C., Guan, D., Qiu, A., and He, S. 2013. CaWRKY58, encoding a group I WRKY transcription factor of Capsicum annuum, negatively regulates resistance to Ralstonia solanacearum infection. Mol. Plant Pathol. 14:131-144.

Wei, T., Ou, B., Li, J., Zhao, Y., Guo, D., Zhu, Y., Chen, Z., Gu, H., Li, C., Qin, G., and Qu, L. J. 2013. Transcriptional profiling of rice early response to Magnaporthe oryzae identified OsWRKYs as important regulators in rice blast resistance. PLoS One 8:e59720.

Wu, J. L., Sinha, P. K., Variar, M., Zheng, K. L., Leach, J. E., Courtois, B., and Leung, H. 2004. Association between molecular markers and blast resistance in an advanced backcross population of rice. Theor. Appl. Genet. 108:1024-1032.

Xie, X. Z., Xue, Y. J., Zhou, J. J., Zhang, B., Chang, H., and Takano, M. 2011. Phytochromes regulate SA and JA signaling pathways in rice and are required for developmentally controlled resistance to Magnaporthe grisea. Mol. Plant 4:688-696.

Yang, X., Wang, W., Coleman, M., Orgil, U., Feng, J., Ma, X., Ferl, R., Turner, J. G., and Xiao, S. 2009. Arabidopsis 14-3-3 lambda is a positive regulator of RPW8-mediated disease resistance. Plant J. 60: 539-550.

Yao, Y., Du, Y., Jiang, L., and Liu, J. Y. 2007. Molecular analysis and expression patterns of the 14-3-3 gene family from Oryza sativa. J. Biochem. Mol. Biol. 40:349-357.

Young, N. D. 1996. QTL mapping and quantitative disease resistance in plants. Annu. Rev. Phytopathol. 34:479-501. 
Yu, F., Huaxia, Y., Lu, W., Wu, C., Cao, X., and Guo, X. 2012. GhWRKY15, a member of the WRKY transcription factor family identified from cotton (Gossypium hirsutum L.), is involved in disease resistance and plant development. BMC Plant Biol. 12:144.

Zhao, J., Davis, L. C., and Verpoorte, R. 2005. Elicitor signal transduction leading to production of plant secondary metabolites. Biotechnol. Adv. 23:283-333.

Zheng, Z., Qamar, S. A., Chen, Z., and Mengiste, T. 2006. Arabidopsis WRKY33 transcription factor is required for resistance to necrotrophic fungal pathogens. Plant J. 48:592-605.
Zhuang, J.-Y., Ma, W.-B., Wu, J.-L., Chai, R.-Y., Lu, J., Fan, Y.-Y., Jin, M.-Z., Leung, H., and Zheng, K.-L. 2002. Mapping of leaf and neck blast resistance genes with resistance gene analog, RAPD and RFLP in rice. Euphytica 128:363-370.

\section{AUTHOR-RECOMMENDED INTERNET RESOURCES}

MSU Rice Genome Annotation Project: http://rice.plantbiology.msu.edu PLACE database: http://www.dna.affrc.go.jp/PLACE 